\title{
The Assessment for Disinvestment of Intramuscular Interferon Beta for Relapsing-Remitting Multiple Sclerosis in Brazil
}

\author{
Livia Lovato Pires de $\operatorname{Lemos}^{1,2}$ (D) Augusto Afonso Guerra Júnior ${ }^{1,3}{ }^{(1)}$ \\ Marisa Santos $^{4}$ (D) Carlos Magliano $^{4}$ (D) Isabela Diniz ${ }^{1,3}$ (D) Kathiaja Souza $^{5,6}$ (D) $^{\circ}$ \\ Ramon Gonçalves Pereira ${ }^{1}$ (D) $\cdot$ Juliana Alvares $^{1,3}$ (D) Brian Godman $^{7,8,9}$. \\ Marion Bennie $^{8}$ (D) Ivan Ricardo Zimmermann ${ }^{5}$ (D) Vânia Crisitna Canuto dos Santos ${ }^{5}$. \\ Clarice Alegre Pretramale ${ }^{5}$ Francisco de Assis Acurcio ${ }^{1,2,3}$
}

Published online: 14 November 2017

(C) The Author(s) 2017. This article is an open access publication

\begin{abstract}
In Brazil, inclusion and exclusion of health technologies within the Unified Health System (SUS) is the responsibility of the National Committee for Health Technology Incorporation (CONITEC). A recent Cochrane systematic review demonstrated that intramuscular interferon beta 1a (IFN- $\beta$-1a-IM) was inferior to the other beta interferons (IFN- $\beta \mathrm{s}$ ) for multiple sclerosis (MS). As a result, CONITEC commissioned an analysis to review possible disinvestment within SUS. The objective of this
\end{abstract}

Electronic supplementary material The online version of this article (doi:10.1007/s40273-017-0579-0) contains supplementary material, which is available to authorized users.

Brian Godman

Brian.Godman@ki.se; brian.godman@strath.ac.uk;

Brian.Godman@liverpool.ac.uk

Livia Lovato Pires de Lemos

lilolemos@gmail.com

Augusto Afonso Guerra Júnior

augustoguerramg@gmail.com

Marisa Santos

marisaccih@gmail.com

Carlos Magliano

carlosincnats@gmail.com

Isabela Diniz

beladiz@gmail.com

Kathiaja Souza

kathiajamsouza@gmail.com

Ramon Gonçalves Pereira

ramonbhb@gmail.com

Juliana Alvares

jualvares@gmail.com

Marion Bennie

marion.bennie@strath.ac.uk paper is to describe the disinvestment process for IFN- $\beta$ 1a-IM in Brazil. The first assessment comprised a literature review and mixed treatment comparison meta-analysis. The outcome of interest was the proportion of relapse-free patients in 2 years. This analysis confirmed the inferiority of IFN- $\beta$-1a-IM. Following this, CONITEC recommended disinvestment, with the decision sent for public consultation. More than 3000 contributions were made on CONITEC's webpage, most of them against the preliminary decision. As a result, CONITEC commissioned a study to assess the effectiveness of IFN- $\beta$-1a-IM among Brazilian patients in routine clinical care. The second assessment

Ivan Ricardo Zimmermann

ivanzricardo@gmail.com

Vânia Crisitna Canuto dos Santos

vania.canuto@saude.gov.br

Clarice Alegre Pretramale

clarice.petramale@saude.gov.br

Francisco de Assis Acurcio

fracurcio@gmail.com

1 SUS Collaborating Centre for Technology Assessment and Excellence in Health, sala 1042, Faculdade de Farmácia, Universidade Federal de Minas Gerais, Av. Presidente Antônio Carlos, 6627, Campus Pampulha, Belo Horizonte, Minas Gerais CEP 31270-901, Brazil

2 Programa de Pós-Graduação em Saúde Pública, sala 533, Faculdade de Medicina, Universidade Federal de Minas Gerais, Av. Porf. Alfredo Balena, 190 , Campus Saúde, Belo Horizonte, Minas Gerais CEP 30130-100, Brazil

3 Programa de Pós-Graduação em Medicamentos e Assistência Farmacêutica, sala 1023, Faculdade de Farmácia, Universidade Federal de Minas Gerais, Av. Presidente Antônio Carlos, 6627, Campus Pampulha, Belo Horizonte, Minas Gerais CEP 31270-901, Brazil 
involved an 11-year follow-up of a non-concurrent cohort of 12,154 MS patients developed by deterministic-probabilistic linkage of SUS administrative databases. The realworld assessment further demonstrated that IFN- $\beta$ - $1 \mathrm{a}-\mathrm{IM}$ users had a statistically higher risk of treatment failure, defined as treatment switching or relapse treatment or death, with the assessment showing that IFN- $\beta-1 \mathrm{a}-\mathrm{IM}$ was inferior to the other IFN- $\beta$ s and to glatiramer acetate in both direct and indirect analysis. In the drug ranking with 40,000 simulations, IFN- $\beta$ - $1 \mathrm{a}-\mathrm{IM}$ was the worst option, with a success rate of only $152 / 40,000$. Following this, CONITEC decided to exclude the intramuscular presentation of IFN- $\beta$ from the current MS treatment guidelines, giving patients who are currently on this treatment the option of continuing until treatment failure. In conclusion, we believe this is the first example of this new disinvestment process in action, providing an exemplar for other treatments in Brazil as well as other countries.

\section{Key Points}

In Brazil, the Unified Health System (SUS) provides treatment for multiple sclerosis (MS), including three pharmaceutical presentations of interferon beta (IFN- $\beta$ ) as first-line treatment; evidence showing inferiority of the intramuscular presentation impelled the National Committee for Health Technology Incorporation (CONITEC) to assess it for possible disinvestment.

Direct and indirect meta-analysis (mixed treatment comparison) with 11 trials showed intramuscular IFN- $\beta$ had the worst outcomes when compared to other forms of IFN- $\beta$; however, this evidence was not sufficient to convince more than 3000 contributors to the public consultation.

The meta-analysis combined with 11-year real-world evidence from more than 12,000 Brazilian MS patients showed that intramuscular IFN- $\beta$ users had a higher chance of treatment failure.

CONITEC decided to disinvest in the intramuscular presentation of IFN- $\beta$ on the basis of further evidence; this was the first case of real-world evidence guiding a disinvestment decision in Brazil.

\section{Introduction}

\subsection{Background (General)}

Since the creation of the National Committee for Health Technology Incorporation (CONITEC, Comissão Nacional de Incorporação de Tecnologias no SUS) in the Brazilian Public Health System (SUS, Sistema Único de Saúde) in 2011 [1], Brazil has had a structured process for the incorporation of different health technologies into SUS. CONITEC includes representatives of the Brazilian Ministry of Health $(\mathrm{MoH})$ and other public entities, the Federal Council of Medicine (CFM, Conselho Federal de Medicina) and patient representatives through the National Health Council (CNS, Conselho Nacional de Saúde). Up to March 2017, CONITEC has recommended the incorporation of 197 health technologies and disinvestment of 43, which have all been accepted by the Secretary of Science, Technology and Strategic Inputs (SCTIE) of the MoH. Disinvested technologies have comprised obsolete/abandoned and/or unsafe technologies. This terminology is similar to that of other studies, acknowledging that many different terms have been used to describe disinvestment, making this a challenging area across countries [2-5]. 
CONITEC procedures are established in law, and there are internal regulations [6]. The Department of Management and Incorporation of Health Technologies of the SCTIE (DGITS/SCITE) forms the Executive Secretariat of CONITEC, and is responsible for the management and coordination of its activities, including formulating investment and disinvestment requests. After formulating or receiving a request for incorporation, disinvestment or an alteration, whether from public bodies, private entities, manufacturers, patient society or citizens, the DGITS/ SCTIE delegates the assessment of the evidence to its own technicians or to a partner research centre that has no conflict of interest with the assessed technology. After the first analysis, CONITEC gathers to debate the preliminary decision. This primary decision is available for public consultation and also available as a patient information leaflet with a complete health technology assessment report [6].

The queries arising from the consultation are answered by the same technicians or researchers that assessed the technology. The deliberations are subsequently presented to the members of the Commission, who either reach a final recommendation or ask for more evidence. After a final recommendation is made, the secretary of SCTIE evaluates it and has its decision published in the official gazette. Following this, the government has 180 days to initiate the implementation process [6].

One such decision was the recent disinvestment of intramuscular interferon beta $1 \mathrm{a}$ (IFN- $\beta$-1a-IM) for treatment of multiple sclerosis (MS). To date, such procedures and deliberations in Brazil have not been published.

Consequently, this paper presents a summary of the detail disinvestment process of IFN- $\beta$-1a-IM for treatment of MS in Brazil and CONITEC's final recommendation following identification as a potential disinvestment opportunity. This builds on the recently agreed process for disinvestment decisions in Brazil [7], as well as recent systematic and other reviews in the area of disinvestment [2-5]. We believe these activities will be of interest to other governments and agencies seeking to instigate disinvestment of less effective and/or less valued technologies as they strive to provide universal healthcare with finite resources.

\subsection{Background to the Disinvestment Decision}

In Brazil, the prevalence of MS ranges from 1.36/100,000 inhabitants to 27.2/100,000 inhabitants, depending on the locality [8]. MS is primarily an autoimmune inflammatory disorder of the brain and spinal cord in which focal lymphocytic infiltration leads to damage of myelin and axons [9-11]. Studies show that, without treatment, MS leads to irreversible disability in 15-20 years from diagnosis
[12-14]. The course of MS is highly varied and unpredictable, and there are three main forms: relapsing-remitting multiple sclerosis (RRMS), primary progressive multiple sclerosis (PPMS), and secondary progressive multiple sclerosis (SPMS). These forms can be active or not active, and they are determined by clinical relapses or magnetic resonance imaging (MRI) activity. There are also two other classifications: clinically isolated syndrome (CIS) and radiologically isolated syndrome (RIS) [15]. In most patients, the disease is characterised initially by episodes of reversible neurological deficits (RRMS form), which are often followed by progressive neurological deterioration over time (SPMS form) [16].

The goal of the treatment of MS is disease remission, defined as a complete absence of relapses, MRI evidence of disease activity, or progression of disability [17]. Switching disease-modifying treatment as soon as there is treatment failure (defined as an occurrence of relapse, worsening of disease activity, progress of the disability, or intolerability) is highly recommended $[18,19]$. SUS currently provides interferon beta (IFN- $\beta$ ) free of charge for the treatment of RRMS and SPMS forms of MS for patients meeting guideline criteria, and until 2010, only three presentations of IFN- $\beta$ and glatiramer acetate were available to patients compliant with the Brazilian clinical protocol for the diagnosis and treatment of MS as first- or second-line treatment (patients could start with either one of the treatments and change to the other in the case of treatment failure) [20]. Other treatments incurred $100 \%$ co-payment. In 2010, natalizumab was made available as third-line treatment, and in 2014, fingolimod was included for natalizumab failures [21].

Despite more than 12 different disease-modifying therapies currently available to treat MS, and more new medicines expected soon [18], IFN- $\beta$ and glatiramer acetate [11] remain first-line options for patients in most clinical settings, and are considered to be equally effective. In Brazil, the updated guideline clearly states that IFN- $\beta-1 \mathrm{a}-$ IM, subcutaneous interferon beta 1 a (IFN- $\beta$-1a-SC), subcutaneous interferon beta $1 \mathrm{~b}$ (IFN- $\beta$ - $1 \mathrm{~b}-\mathrm{SC}$ ) and glatiramer acetate are similarly effective, with their differences being in their administration schedules and adverse event profiles [21-24].

However, in 2015, a Cochrane systematic review [25] showed that the IFN- $\beta$ given once a week intramuscularly (IFN- $\beta$-1a-IM) was inferior to other interferons given in a more intense schedule subcutaneously. Because of this evidence, the $\mathrm{MoH}$ in Brazil sought to evaluate the scientific and clinical data regarding the effectiveness of IFN- $\beta$ for MS for analysis by the CONITEC. The applicant for this potential disinvestment was the SCTIE of MoH, and the first assessment team was the Health Technology Assessment Centre of the Brazilian National Institute of 
Cardiology (NATS-INC), with additional information requested from the SUS Collaborating Centre for Technology Assessment and Excellence in Health of the Federal University of Minas Gerais (CCATES-UFMG).

When the MoH analysed the possibility to disinvest in IFN- $\beta$-1a-IM following the Cochrane review being brought to its attention [25], the objective was to evaluate the effectiveness of this presentation compared with other firstor second-line treatments (IFN- $\beta-1 \mathrm{a}-\mathrm{SC}$, IFN- $\beta-1 \mathrm{~b}-\mathrm{SC}$ and glatiramer). Although the costs of each treatment are different (being between US $\$ 4763.81$ and US $\$ 7394.20$ for subcutaneous IFN- $\beta$, US $\$ 6829.23$ for intramuscular IFN- $\beta$ and US\$6201.26 for glatiramer per patient per year) ${ }^{1}$, improving cost-effectiveness was not the principal goal. The potential use of less effective interventions for such a severe and debilitating disease was the major driver for the $\mathrm{MoH}$ to review potential disinvestment. However, reduced effectiveness would impact on overall cost-effectiveness when the cost of relapses, including further treatments, were considered.

The first step undertaken in the disinvestment process was the analysis of the efficacy of the different available treatments, building on the Cochrane review [25]. Since the Cochrane review compared 15 immunomodulators/immunosuppressants, a literature review of the efficacy and safety of IFN- $\beta$ was initially made. Since head-to-head trials were scarce, the NATS-INC team opted to complement this approach with indirect comparisons, which confirmed the inferiority of the IFN- $\beta-1 \mathrm{a}-\mathrm{IM}$. Following this, CONITEC decided to exclude this pharmaceutical presentation from the national guideline, and sent the report for public consultation. Within 20 days, more than 3000 comments had been submitted onto the CONITEC webpage, most of them against the preliminary decision. The controversy caused by the possible exclusion of IFN$\beta$-1a-IM made it necessary to more vigorously examine the evidence for the performance of IFN- $\beta$ in the Brazilian population by means of a nationwide cohort analysis. This formed the second part of the newly agreed disinvestment process in Brazil [7].

\section{Disinvestment Process}

The process flow for the disinvestment process for IFN- $\beta$ 1a-IM is summarised in Fig. 1.

\footnotetext{
${ }^{1}$ Brazilian Real (BRL) = US\$0.3126563; Banco Central do Brasil, 28/04/2017.
}

\subsection{First Assessment}

\subsubsection{First Assessment: Methodology}

NATS-INC personnel searched the references of the Cochrane systematic review and performed a search on March 2015 for new clinical trials in the Medline database, using the following terms: ((Rebif[Title] OR Avonex[Title]) OR Betaferon[Title]) OR Betaferon[Title] AND (Clinical Trial[ptyp] AND "humans"[MeSH Terms]). To qualify for inclusion, studies had to be randomised controlled trials comparing IFN- $\beta$ s with each other or with glatiramer acetate or with placebo in the treatment of RRMS in adults. Clinical trials were excluded if they evaluated IFN- $\beta$ given in a dosing scheme different to those recommended in the Brazilian clinical guideline $[20,21]$.

The outcome of interest was the proportion of relapsefree patients in 2 years. This usually is the primary outcome of RRMS clinical trials and reflects the importance of relapses to the increase in incapacity [25]. Risk of bias was assessed using the Cochrane Collaboration risk of bias tool [26] that comprises the evaluation of selection bias (sequence generation and allocation concealment), performance bias (blinding of participants and personnel), detection bias (blinding of the outcome assessment), attrition bias (incomplete outcome data), and reporting bias (selective outcome reporting).

We compared IFN- $\beta$ s directly using a frequentist approach, and compared them indirectly using a Bayesian method. For the direct comparison, a meta-analysis was performed between the trials, and we adopted a conservative approach using the Mantel-Haenszel method with random effect model, with the $95 \%$ confidence interval (CI) and data presented in decreasing order of magnitude of effect, with the aid of Review Manager ${ }^{\circledR} 5.0$ software. For the indirect comparison, the mixed treatment comparison (MTC) was used, with the graphical interface MTC Jags developed by the NATS-INC, available for free use at R 3.3.3 packages ('RcmdrPlugin.RMTCJags'). Among all methods of indirect comparisons, this is the most versatile and robust [27]. To improve robustness, glatiramer acetate was included in the network of treatments. Data extraction and analysis of measures of effect were performed by intention to treat (ITT).

\subsubsection{First Assessment: Results}

We identified 11 trials: ten included in the Cochrane review [23-25, 28-35] and one other [36] after searching Medline (Table 1). Four studies [28, 29, 33, 34] and one other study [31] were classified as presenting, respectively, unclear risk and high risk of selection bias with respect to random 
Table 1 Results of the studies included in the meta-analysis

\begin{tabular}{|c|c|c|c|}
\hline Study (author) & Treatment & No. & Relapse free $[n(\%)]$ \\
\hline \multirow[t]{2}{*}{ The IFNB Multiple Sclerosis Study Group, [28] } & IFN- $\beta-1 b-S C$ & 115 & $36(31.3)$ \\
\hline & Placebo & 112 & $18(16.1)$ \\
\hline Jacobs et al. [29] & IFN- $\beta-1 \mathrm{a}-\mathrm{IM}$ & 158 & $32(20.3)$ \\
\hline \multirow[t]{2}{*}{ PRISMS Study Group [30] } & IFN- $\beta-1 \mathrm{a}-\mathrm{SC}$ & 187 & $60(32.1)$ \\
\hline & Placebo & 187 & $30(16.0)$ \\
\hline \multirow[t]{4}{*}{ Khan et al. [31] } & Placebo & 33 & $1(3.0)$ \\
\hline & IFN- $\beta-1 \mathrm{a}-\mathrm{IM}$ & 40 & $4(10.0)$ \\
\hline & IFN- $\beta-1 b-S C$ & 41 & $11(26.8)$ \\
\hline & Glatiramer & 42 & $13(31.0)$ \\
\hline \multirow[t]{2}{*}{ INCOMIN (Durelli et al.) [32] } & IFN- $\beta-1 b-S C$ & 96 & $49(51.0)$ \\
\hline & IFN- $\beta-1 \mathrm{a}-\mathrm{IM}$ & 92 & $33(35.9)$ \\
\hline \multirow[t]{2}{*}{ Koch-Henriksen et al. [33] } & IFN- $\beta-1 \mathrm{a}-\mathrm{SC}$ & 143 & $64(44.8)$ \\
\hline & IFN- $\beta-1 b-S C$ & 158 & $77(48.7)$ \\
\hline \multirow[t]{3}{*}{ Etemadifar et al. [34] } & IFN- $\beta-1 \mathrm{a}-\mathrm{SC}$ & 30 & $17(56.7)$ \\
\hline & IFN- $\beta-1 b-S C$ & 30 & $13(43.3)$ \\
\hline & IFN- $\beta-1 \mathrm{a}-\mathrm{IM}$ & 30 & $6(20.0)$ \\
\hline \multirow[t]{2}{*}{ EVIDENCE (Schwid et al.) [35] } & IFN- $\beta-1 \mathrm{a}-\mathrm{SC}$ & 339 & $191(56.3)$ \\
\hline & IFN- $\beta-1 \mathrm{a}-\mathrm{IM}$ & 338 & $163(48.2)$ \\
\hline \multirow[t]{2}{*}{ REGARD (Mikol et al.) [23] } & IFN- $\beta-1 \mathrm{a}-\mathrm{SC}$ & 386 & $260(67.4)$ \\
\hline & Glatiramer & 378 & $246(65.1)$ \\
\hline \multirow[t]{2}{*}{ BEYOND (O'Connor et al.) [24] } & IFN- $\beta-1 b-S C$ & 897 & $520(58.0)$ \\
\hline & Glatiramer & 448 & $264(58.9)$ \\
\hline \multirow[t]{2}{*}{ CombiRx (Lubin et al.) [36] } & IFN- $\beta-1 \mathrm{a}-\mathrm{IM}$ & 250 & $185(74.0)$ \\
\hline & Glatiramer & 259 & $206(79.5)$ \\
\hline
\end{tabular}

$I F N-\beta$ interferon beta, $I M$ intramuscular, $S C$ subcutaneous

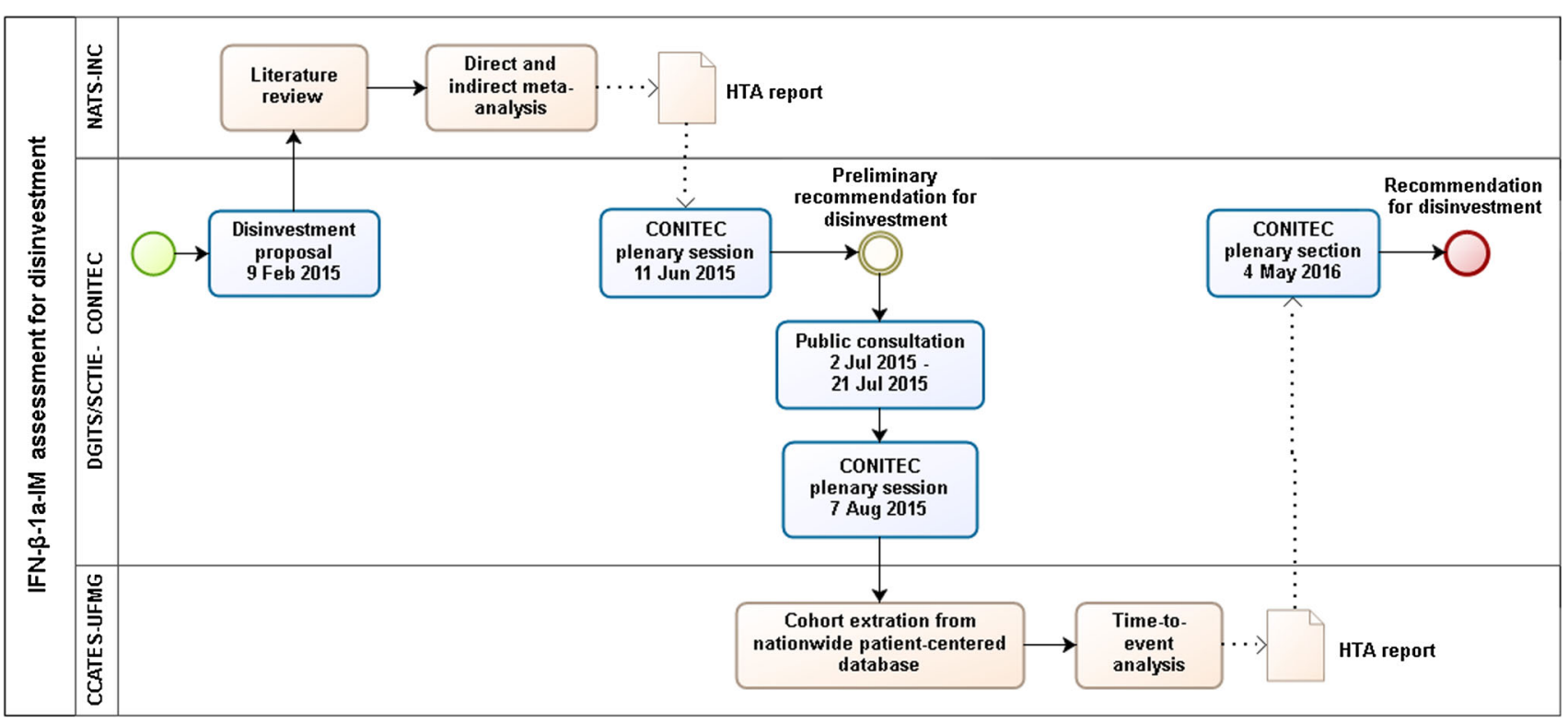

Fig. 1 Work plan for the disinvestment of IFN- $\beta$-1a-IM in Brazil. CCATES-UFMG Collaborating Centre for Technology Assessment and Excellence in Health of the Federal University of Minas Gerais, CONITEC National Committee for Health Technology Incorporation, DGITS/SCITE Department of Management and Incorporation of
Health Technologies of the SCTIE, HTA health technology assessment, IFN- $\beta-1 a-I M$ intramuscular interferon beta 1a, NATS-INC Health Technology Assessment Centre of the Brazilian National Institute of Cardiology, SCTIE Secretary of Science, Technology and Strategic Inputs 


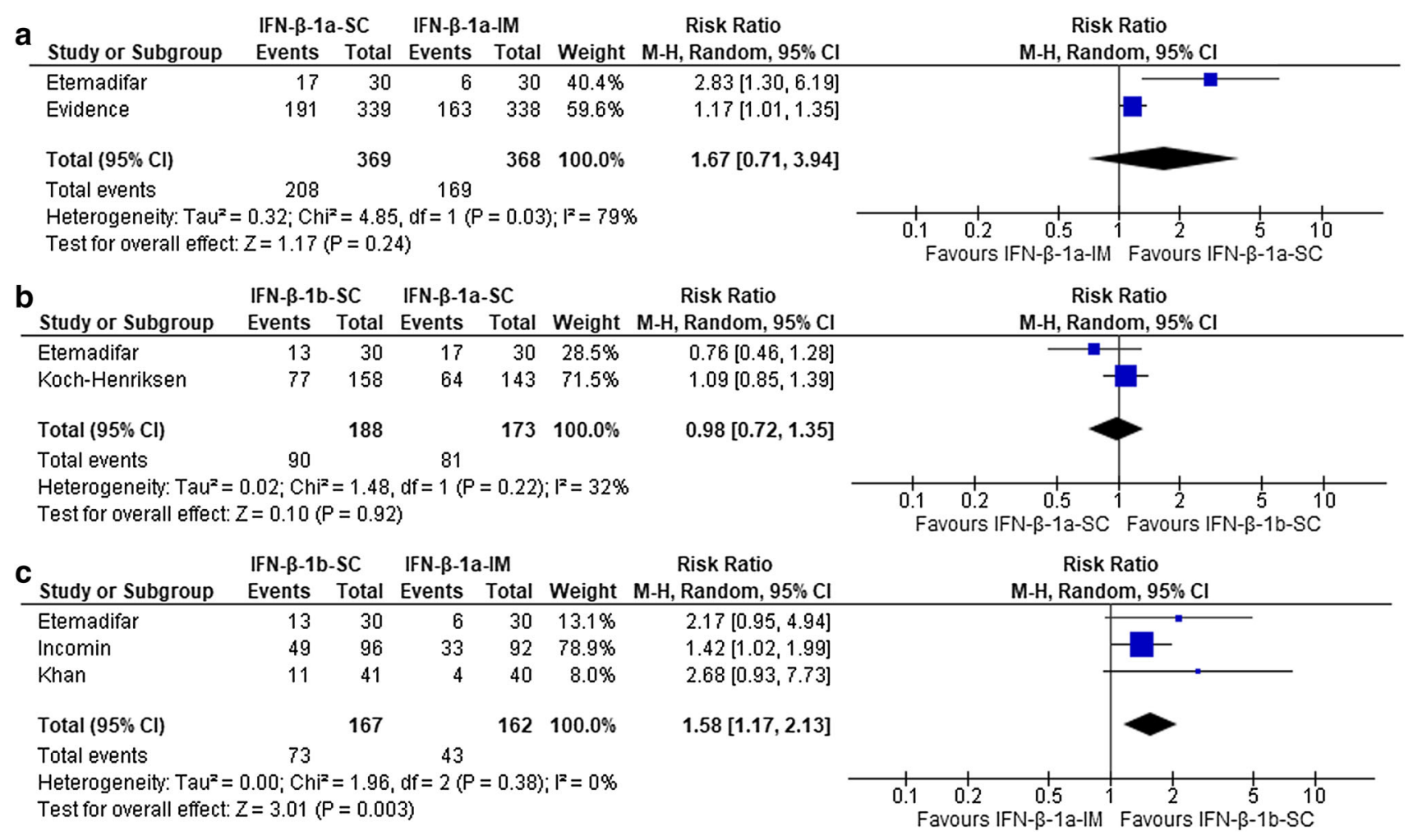

Fig. 2 Forest plots of direct comparison meta-analysis of the proportion of patients relapse-free after 2 years of treatment: a IFN$\beta$-1a-SC vs IFN- $\beta$ - $1 \mathrm{a}-\mathrm{IM}$; b IFN- $\beta$ - 1 b-SC vs IFN- $\beta-1 \mathrm{a}-\mathrm{SC}$; $\mathbf{c}$ IFN- $\beta$ -
1b-SC vs IFN- $\beta$-1a-IM. $C I$ confidence interval, $I F N-\beta$ interferon beta, $I M$ intramuscular, $S C$ subcutaneous

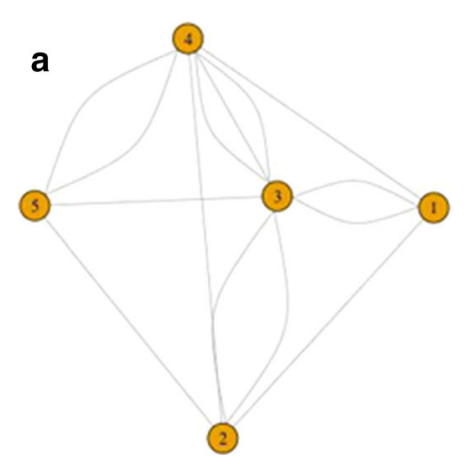

b

$\begin{array}{lrr}\text { Comparisons } & \text { OR } & \text { LClr_OR } \\ \text { OR_2_1 } & 2.64 & 1.49 \\ \text { OR_3_1 } & 2.42 & 1.38 \\ \text { OR_4_1 } & 1.65 & 0.95 \\ \text { OR_5_1 } & 2.61 & 1.37 \\ \text { OR_3_2 } & 0.92 & 0.41 \\ \text { OR_4_2 } & 0.63 & 0.28 \\ \text { OR_5_2 } & 0.99 & 0.42 \\ \text { OR_4_3 } & 0.68 & 0.31 \\ \text { OR_5_3 } & 1.08 & 0.46 \\ \text { OR_5_4 } & 1.58 & 0.68\end{array}$

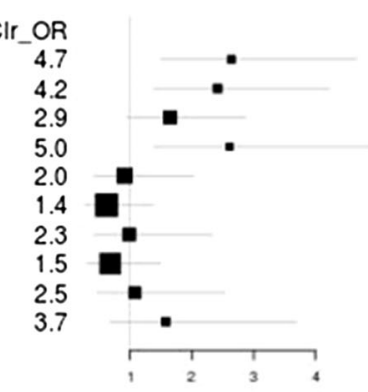

$2=$ IFN- $\beta$ - $1 \mathrm{a}-\mathrm{SC} ; 3=$ IFN- $\beta-1 \mathrm{~b}-\mathrm{SC} ; 4=\mathrm{IFN}-\beta-1 \mathrm{a}-\mathrm{IM} ; 5=$ glatiramer acetate. IFN- $\beta$ interferon beta, IM intramuscular, $S C$ subcutaneous

From the analysis, it is possible to observe the superiority of IFN- $\beta$ - $1 \mathrm{~b}-\mathrm{SC}$ in relation to IFN- $\beta$ - $1 \mathrm{a}-\mathrm{IM}$ [risk ratio (RR) $1.58,95 \%$ CI 1.17-2.13], and no significant difference was observed among the other comparisons (Fig. 2).

The indirect comparison shows superiority of IFN- $\beta$ - $1 \mathrm{a}-$ SC, IFN- $\beta-1 b-S C$ and glatiramer compared to placebo. Given the probability distribution characteristic of the odds 
ratio comparison, where the probability of the outcome is greater around the central measure of the credibility interval, the data suggest that IFN- $\beta-1 \mathrm{a}-\mathrm{IM}$ is superior to placebo, and IFN- $\beta-1 \mathrm{a}-\mathrm{SC}$ and IFN- $\beta-1 \mathrm{~b}-\mathrm{SC}$ are superior to IFN- $\beta$-1a-IM (Fig. 3 and Supplementary Material Figures $3 \mathrm{~A}$ and $4 \mathrm{~A})$.

A total of 40,000 simulations were carried out to estimate drug rankings. The treatment with the highest success rate was IFN- $\beta-1 \mathrm{a}-\mathrm{SC}$, with a $43 \%$ success rate, or the best option in 17,200 of the 40,000 simulations; glatiramer acetate was the drug with the second highest success rate. Among the IFN- $\beta$ s, IFN- $\beta-1 b-S C$ was the second best option in most of the simulations $(7804 / 40,000)$ and the worse option was IFN- $\beta$-1a-IM, with a success rate of only $152 / 40,000$.

Considering the results, CONITEC recommended that the findings be made available in a public consultation, with the initial recommendation to disinvest in IFN- $\beta$ - 1 aIM for the treatment of MS in the SUS guidance, due to its inferiority in relation to the other IFN- $\beta$ s.

\subsection{Public Consultation}

From September 7 to October 10, 2015, more than 3000 comments were received from the public consultation. Most of them brought reports and lawsuits for the maintenance of IFN- $\beta-1 \mathrm{a}-\mathrm{IM}$ and its indication in SUS, arguing that its possible withdrawal would be harmful to those who were already on this IFN- $\beta$ and were getting some benefit. However, such claims did not provide adequate justification or scientific evidence for continued funding. The comments raised other issues favourable to the use of IFN$\beta$-1a-IM. These included being the medicine of choice in pregnancy, good response of the drug (with reduction of outbreaks and that its exchange would probably trigger outbreaks), and better convenience of use (adherence) and quality of life (for being administered intramuscularly once a week).

Regarding these issues:

1. For the use of IFN- $\beta-1 \mathrm{a}-\mathrm{IM}$ in pregnancy, according to the current recommendations of the current Brazilian guideline, there is no IFN- $\beta$ of choice for use during this period, and it is recommended not to use immunomodulators, because they have an unfavourable safety profile during pregnancy, and its use is restricted to cases in which the clinical evolution of the disease has been unfavourable [21]. Similarly, according to the current text of the package leaflet of IFN- $\beta$ 1a-IM, discontinuation of treatment is the current recommendation, since available data also indicate that there may be an increased risk of spontaneous abortion.
2. There is no robust evidence to support that there will be harm to the patient if there is substitution of IFN- $\beta$ 1a-IM for another IFN- $\beta$.

3. There is also no robust evidence to prove greater adherence to IFN- $\beta-1 \mathrm{a}-\mathrm{IM}$ and its consequences in a review of the scientific literature.

After the public consultation, the results were again discussed by members of CONITEC on October 10, 2015. Following this, given the content of the public consultation (mostly contrary to the preliminary recommendation for exclusion), the Commission chose to seek more information, including a new study on the effectiveness of the IFN$\beta s$ in the real-world to enhance the robustness of any final recommendation.

\subsection{Second Assessment: Real-World Study}

\subsubsection{Second Assessment: Methodology}

CCATES-UFMG personnel developed a national nonconcurrent open cohort study including adult RRMS patients (IDC-10 G35) who were treated with IFN- $\beta$ s in Brazil from $1 / 1 / 2000$ to $12 / 31 / 2010$. The follow-up time was from $1 / 1 / 2000$ to $12 / 31 / 2010$, consequently, covering 11 years. As previously mentioned, during this period only IFN- $\beta$ s and glatiramer acetate were available through the SUS, and in the case of treatment failure, patients were allowed to switch among them.

This cohort was developed by deterministic-probabilistic linkage of the following SUS administrative databases: Hospital Information System (SIH), Ambulatory Information System (SIA), and Mortality Information System (SIM) $[28,29]$. The variables used for linkage were name, name of the mother, date of birth, and the individual taxpayer registration number. IFN- $\beta$ is dispensed on a monthly basis. The entry date was the date of the first drug dispensed. For the evaluation of effectiveness, the event used for survival analysis was treatment failure, identified by treatment switching or relapse treatment or death, whichever occurred first. Patients were allowed 3 consecutive months without medicine until they switched drugs. The date of the last registry of drug dispensing was entered if patients abandoned their treatment or interrupted their treatment for 4 or more months (censored). Right censoring was established on 12/31/2010 (end of follow-up).

Patients were analysed according to the IFN- $\beta$ at study entry. For the evaluation of effectiveness, we performed two sensitivity analyses. In the first one, we adopted a 'new user' design by excluding patients who started therapy between $1 / 1 / 2000$ and 12/31/2001. In the second, we did not impose a time limit without a dispensing registry for event assignment, that is, patients were not censored for 
Table 2 Baseline characteristics of Brazilian patients with relapsingremitting multiple sclerosis included in the study, 2000-2010

\begin{tabular}{llll}
\hline Variable & $\begin{array}{l}\text { IFN- } \beta-1 \mathrm{a}-\mathrm{SC} \\
n=5557\end{array}$ & $\begin{array}{l}\text { IFN- } \beta-1 \mathrm{~b}-\mathrm{SC} \\
n=3372\end{array}$ & $\begin{array}{l}\text { IFN- } \beta-1 \mathrm{a}-\mathrm{IM} \\
n=3225\end{array}$ \\
\hline $\begin{array}{l}\text { Mean age, years } \pm \mathrm{SD}^{\mathrm{a}} \\
\text { Age group, } n(\%)\end{array}$ & $39.0 \pm 11.4$ & $39.3 \pm 11.1$ & $38.4 \pm 11.4$ \\
$18-29$ & $1307(23.5)$ & $747(22.2)$ & $811(25.1)$ \\
$30-39$ & $1591(28.6)$ & $959(28.4)$ & $975(30.2)$ \\
$40-49$ & $1625(29.2)$ & $1065(31.6)$ & $880(27.3)$ \\
$50-59$ & $815(14.7)$ & $482(14.3)$ & $433(13.4)$ \\
$60+$ & $219(3.9)$ & $119(3.5)$ & $126(3.9)$ \\
Sex, female, $n(\%)^{\mathrm{b}}$ & $4037(72.6)$ & $2404(71.3)$ & $2444(75.8)$ \\
Geographic region of residence, $n(\%)$ & & $15(0.4)$ \\
North & $114(2.0)$ & $41(0.9)$ & $277(8.4)$ \\
Northeast & $867(15.0)$ & $374(10.6)$ & $284(8.8)$ \\
Central-West & $554(10.5)$ & $349(11.0)$ & $711(22.3)$ \\
South & $919(16.5)$ & $651(19.9)$ & $1938(60.2)$ \\
Southeast & $3103(56.0)$ & $1957(57.6)$ & $724(19.3)$ \\
Calendar period of cohort entry, $n(\%)$ & & $2501(80.7)$ \\
2000-2004 & $2716(44.8)$ & $1892(60.6)$ & \\
2005-2010 & $2811(55.2)$ & & \\
\hline
\end{tabular}

$I F N-\beta$ interferon beta, $I M$ intramuscular, $S C$ subcutaneous, $S D$ standard deviation

${ }^{\mathrm{a}} t$ test: IFN- $\beta$-1a-IM vs IFN- $\beta$-1b-SC, $p=0.0024$; IFN- $\beta$-1a-IM vs IFN- $\beta-1 \mathrm{a}-\mathrm{SC}, p=0.0217$; IFN- $\beta$ - $1 \mathrm{~b}$ SC vs IFN- $\beta$ - $1 \mathrm{a}-\mathrm{SC}, p=0.2928$

${ }^{\mathrm{b}}$ Chi-square: IFN- $\beta$-1a-IM vs IFN- $\beta$-1b-SC, $p=0.000036$; IFN- $\beta$-1a-IM vs IFN- $\beta$ - $1 \mathrm{a}-\mathrm{SC}, p=0.001275$; IFN- $\beta$-1b-SC vs IFN- $\beta-1 \mathrm{a}-\mathrm{SC}, p=0.166474$ abandonment if they returned to the index IFN- $\beta$ or switched drugs at any time after interrupting their first treatment. If they did not return to treatment, they were censored for loss to follow-up.

For treatment persistence, the event used for survival analysis was treatment switching, treatment abandonment or treatment interruption, whichever occurred first. Patients were censored at the date of death or on 12/31/2010. Oneyear and 2-year treatment persistence were calculated by dividing the number of patients still on their index IFN- $\beta$ by the number of patients with at least 12 or 24 months of follow-up.

We calculated the frequency distributions for the categorical variables, and the mean and standard deviation (SD) for the continuous variables. Student's $t$ test was used to assess differences between the means of the two groups, and the chi-square test was used to evaluate differences in frequencies. We analysed the influence of the index IFN- $\beta$ and of each descriptive variable in treatment survival using univariate analysis and evaluated their association with treatment failure. The Kaplan-Meier method was used to estimate the cumulative probability of survival. The different survival curves were compared using the log-rank test. The influence of the index IFN- $\beta$ in the occurrence of treatment failure was also assessed using the Cox proportional hazards model and the Wald test. The hazard ratio (HR) for progression to the event was calculated considering a $95 \%$ CI. Statistical analysis was performed using "R" version 3.1.1 (R Foundation for Statistical Computing) and SPSS version 17 (SPSS Inc., Chicago, USA).

\subsubsection{Second Assessment: Interferon Beta Real-World Performance}

From 18,358 identified patients, the following were excluded: 674 patients for being younger than 18 years old at the start of treatment; 3183 patients with less than six procedures for the treatment of MS in the hospital or ambulatory databases; 2176 for having started treatment with glatiramer acetate; and 166 for having started treatment with azathioprine.

Of the 12,154 included patients, the majority started treatment with IFN- $\beta$-1a-SC (45.7\%); followed by IFN- $\beta$ 1b-SC $(27.7 \%)$ and IFN- $\beta-1 \mathrm{a}-\mathrm{IM}(26.5 \%)$. In all groups, most of the patients were female and resided in the Southeast of the country when they entered the cohort. Although the groups statistically differed in their mean age at study entry, the difference was not considered clinically important (Table 2). 


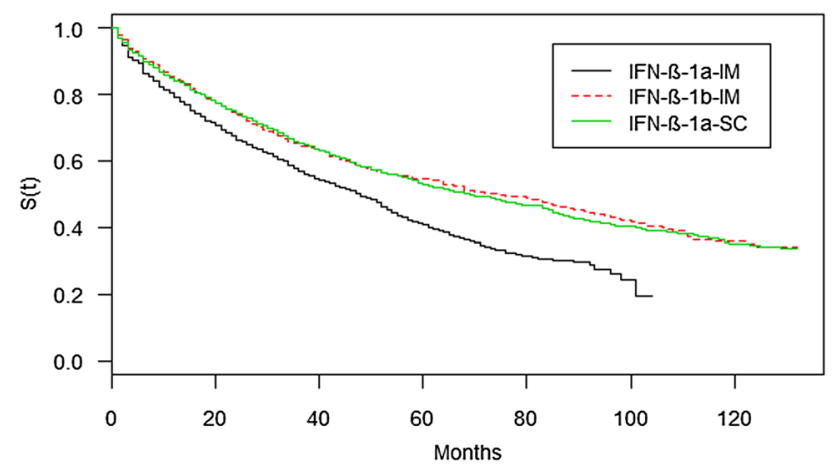

Fig. 4 Kaplan-Meier curves depicting time to treatment failure, defined as treatment switching, relapse or death for IFN- $\beta-1 \mathrm{a}-\mathrm{SC}$, IFN- $\beta-1$ b-SC and IFN- $\beta$-1a-IM. IFN- $\beta$ interferon beta, $I M$ intramuscular, $S C$ subcutaneous, $S(t)$ survival function

The analysis of the Kaplan-Meier curves for IFN- $\beta$ s revealed that IFN- $\beta-1 \mathrm{a}-\mathrm{IM}$ is inferior when compared to the others (log-rank $p<0.0001)$ (Fig. 4). The median time to treatment failure was 47 months (95\% CI 44-52) for IFN- $\beta-1 \mathrm{a}-\mathrm{IM}, 69$ months $(95 \%$ CI $64-76)$ for IFN- $\beta-1 \mathrm{a}-$ SC, and 73 months (95\% CI 66-84) for IFN- $\beta-1 b-S C$ $(p<0.0001$ for both comparisons intramuscular vs subcutaneous).

Univariate analysis revealed that the use of IFN- $\beta-1 \mathrm{a}-$ IM increased the risk of treatment failure (HR 1.381, 95\% CI $1.292-1.475 ; p<0.001$ ), while the use of both subcutaneous IFN- $\beta$ s had a protective effect (reference group 1a: HR $0.864,95 \%$ CI $0.814-0.917$; 1b: HR 0.887, 95\% CI $0.829-0.949 ; p<0.001)$. Both sensitivity analyses revealed similar results to the main analysis (Supplementary Material Figures 5A and 6A).
Persistence analysis revealed that a lower proportion of patients who started treatment with intramuscular IFN- $\beta$ remained in the same treatment at 1 and 2 years from the start of treatment compared with patients using either subcutaneous IFN- $\beta$. There was no statistically significant difference between the subcutaneous presentations (Table 3).

The limitations of these results lie in the fact they were extracted from administrative databases not created for clinical outcomes assessment; consequently, we did not have patient-level variables available, such as MRI results. In addition, we believe that many cases of relapses and adverse events were not registered in SUS databases because some patients were treated in private clinics or hospitals. To overcome this, we chose to use the composite event of treatment failure capturing treatment switching that, as indicated in the clinical protocol, happens in cases of relapse, intolerance or adverse reaction [21].

\subsection{Final Decision}

This evidence was presented to the members of CONITEC on May 4, 2016. The performance assessment ruled out for the majority of the members the option to keep the IFN- $\beta$ 1a-IM in the guideline as it is. The possibility to restrict the use of this medicine to patients non-adherent to treatment with the other IFN- $\beta$ s was debated, but the option to offer a less effective medicine to patients as second-line was firmly rejected.

Next, members debated the implications of full withdrawal of this medicine. The first point raised by one of the members of CONITEC was that by excluding this intramuscular IFN- $\beta$, the Commission was not removing a
Table 3 Twelve and 24 months' persistence in index $I F N-\beta$ of the Brazilian patients with relapsing-remitting multiple sclerosis included in the study, 2000-2010

\begin{tabular}{llll}
\hline Time period & IFN- $\beta-1 \mathrm{a}-\mathrm{SC}$ & IFN- $\beta-1 \mathrm{~b}-\mathrm{SC}$ & IFN- $\beta$-1a-IM \\
\hline 12 months & & & \\
Persistent & $4051(76.6)$ & $2432(77.4)$ & $2092(71.6)$ \\
Total non-persistent & 1235 & 709 & 828 \\
$\quad$ Treatment switching & $774(62.7)$ & $455(64.2)$ & $593(71.6)$ \\
Treatment abandonment & $457(37.0)$ & $253(35.7)$ & $234(28.3)$ \\
Treatment interruption & $4(0.3)$ & $1(0.1)$ & $1(0.1)$ \\
24 months & & & $1244(53.3)$ \\
Persistent & $2864(59.8)$ & $1661(60.5)$ & 1092 \\
Total non-persistent & 1,929 & 1085 & $751(68.8)$ \\
Treatment switching & $1139(59.0)$ & $676(62.3)$ & $341(34.2)$ \\
Treatment abandonment & $786(40.7)$ & $407(37.5)$ & $0(0.0)$ \\
Treatment interruption & $4(0.2)$ & $2(0.2)$ & \\
\hline
\end{tabular}

Values are shown are $n(\%)$

Chi-square for both time periods: IFN- $\beta$-1a-IM vs IFN- $\beta$-1b-SC, $p<0.0001$; IFN- $\beta$-1a-IM vs IFN- $\beta$-1a-SC, $p<0.0001$; IFN- $\beta$ - 1 b-SC vs IFN- $\beta$ - $1 \mathrm{a}-\mathrm{SC}, p>0.05$

$I F N-\beta$ interferon beta, IM intramuscular, $S C$ subcutaneous 
treatment option from patients, since the active ingredient would still be available in subcutaneous presentations. This line of thought was followed by the majority of the members except by those closely related to the health authorities of the States in Brazil, who are responsible for dispensing IFN- $\beta$ and all other high-cost drugs.

The major concern was that patients would go to court against the health authorities of the States in order to keep their treatment and the objective of offering the best possible options to patients would be lost, with this option increasingly used in Brazil to access technologies currently not funded [37]. To address this issue, Commission members decided to exclude the intramuscular presentation of IFN- $\beta$ from the guideline, but give patients who are currently on this treatment the option of continuing until treatment failure. The SCTIE agreed with the decision, which was published in the official gazette on June 8, 2016 [38].

\section{Overview of Disinvestment Process}

IFN- $\beta$-1b-SC was the first treatment approved by the Food and Drug Administration in the USA for RRMS in 1993, followed by IFN- $\beta$-1a-IM in 1996, and by IFN- $\beta$ - 1 a-SC in 2002, all of them with orphan drug designations [39]. In Brazil, these drugs were licensed, respectively, in 1996, 1999, and 1996, and were subsequently incorporated into SUS in 2001 [40], that is, 10 years before the creation of CONITEC and the adoption of a formal health technology assessment process [6].

The reassessment of these medicines occurred 15 years after their incorporation, as appreciably more evidence became available. The meta-analysis of randomised controlled trials showed that IFN- $\beta$-1a-IM may have a success rate similar to placebo, which led to the preliminary recommendation of exclusion of this pharmaceutical presentation. However, this decision was heavily contested in the public consultation. This may have been influenced by a number of MS patient advocacy organisations (PAOs). However, it is difficult to comment further since many of these PAOs do not explicitly declare conflicts of interest on their websites/online pages.

Despite the similar content of most comments in this particular case, public consultation was, and has been, an important tool for citizen participation. In this assessment process, additional information regarding adherence to treatment and safety were further investigated after these points had been raised by public consultation. Even with this new evidence showing that intramuscular IFN- $\beta$ is not as effective and safe as the other available treatments, and does not improve patient adherence, the intensity of the comments in the public consultation led the members of
CONITEC to commission a performance assessment to explore the outcomes of the IFN- $\beta$ s in the Brazilian population in more detail.

The need for a greater theoretical basis for divestment than for investment has already been debated [41], and is one of the many challenges for disinvestment initiatives worldwide. In Brazil, disinvestment decisions are prioritised to occur after the study of the effectiveness of the biomedical interventions in the Brazilian population. This was established as a way to overcome concerns with randomised controlled trials in terms of their lack of external validity, and to reveal to society the real value of a technology, thus providing more convincing and robust evidence [7].

The negative side of this approach is the time needed to generate the evidence and the timing of the decisions. Studying the performance of health technologies in the real world takes time and resources, both of which may hamper disinvestment decisions, as seen in other disinvestment attempts worldwide [2]. This motivated CONITEC to embrace a wider strategy in which prioritised technologies will be assessed for performance for continued investment, probably using partner research centres and funds already available for research of interest to SUS.

Cost constraints have been the most common drivers of disinvestment attempts [3]. In the present case, cost-effectiveness was not an immediate issue, as CONITEC members were interested in assuring that RRMS patients were getting the most effective treatment. We believe that a cost-effectiveness analysis would not be necessary, since all options are already available, that is, patients using intramuscular IFN- $\beta$ would change to either subcutaneous presentation, which were considered cost-effective in the first place. In the report sent to public consultation, it was explained that the preliminary decision to disinvest in intramuscular IFN- $\beta$ was taken "due to its inferiority in relation to the other IFN- $\beta$, despite its lower current cost." This statement sends the message that saving money is not a key point for the $\mathrm{MoH}$ in this case, which probably avoided an even greater commotion in the public consultation. This is in accordance with a recent systematic review of 15 disinvestment programmes/experiences from eight countries where efficacy was the most important criterion for identification, prioritisation and assessment of technologies for disinvestment, followed by economics [3]. Other approaches and processes appear similar [2, 4, 5]. Our process builds on this with additional investigation with real-world evidence [7].

Our findings are in agreement with those of the Canadian Drug Expert Committee from the Canadian Agency for Drugs and Technologies in Health (CADTH), which considered IFN- $\beta$-1b-SC cost-effective and therefore recommend its use as the initial pharmacotherapy of choice 
for the treatment of RRMS. When compared to placebo, both IFN- $\beta-1 b-S C$ and IFN- $\beta-1 a-S C$ produced the same annual rate of relapse; however, IFN- $\beta-1 \mathrm{a}-\mathrm{SC}$ had a higher cost. For the same outcome, IFN- $\beta$-1a-IM was considered less effective when compared directly and indirectly to both subcutaneous forms [42].

In 2002, the National Institute for Health and Care Excellence (NICE) issued a technology appraisal not recommending the use of either IFN- $\beta$ or glatiramer acetate for RRMS [43]. Although no IFN- $\beta$ was considered a costeffective option, IFN- $\beta$ - $1 \mathrm{~b}-\mathrm{SC}$ was seen as the most costeffective among them [43]. In the same year, the UK Department of Health produced a risk-sharing scheme to supply the four medicines at a reasonable cost-effective price within the UK National Health System, with the initial results published in 2009 again suggesting limited effectiveness, with a suggestion of outcomes worse than the untreated comparator group [44, 45]. However, the results of 6 years of follow-up of patients participating in the risk-sharing scheme, published in May 2015, revealed that IFN- $\beta$ (altogether) and glatiramer acetate are cost-effective options, enhanced by including data sets from British Columbia, supporting the decision of CONITEC to continue to fund certain IFN- $\beta$ s [46].

Some months after the $\mathrm{MoH}$ decision to disinvest in intramuscular IFN- $\beta$, the company announced the licensing of its pegylated version in the country. It is interesting to note that this medicine gained access to the Brazilian market, and to many others, after having performed better than placebo [47]. In 2013, IFN- $\beta$-1a-IM was the medicine with the second highest sales worldwide among treatments for MS. IFN- $\beta-1 b-S C$ and IFN- $\beta-1 a-S C$ were fifth and seventh, respectively [48]. According to an IMS health report, MS medicines as a group represented the eighth largest drug spend in the USA in 2015 [49]. This report also foresaw that injectable treatment revenues would fall in the coming years in the USA [49], which will probably also happen in Brazil where fingolimod for second-line treatment (after IFN- $\beta$ or glatiramer failures) and teriflunomide as first-line treatment were incorporated in the first months of 2017 [50, 51]. Interestingly, in Brazil in September 2015, Bio-Manguinhos, a biologics plant of the MoH funding Fundação Oswaldo Cruz (Fiocruz), signed a technology transfer agreement with Merck and Bionovis to produce IFN- $\beta$-1a-IM [52], which was the IFN- $\beta$ initial treatment between 2000 and 2010 .

As with suggestions for potential investment in Brazil, proposals for disinvestment can be suggested by pharmaceutical companies as well as other stakeholders. However, we believe it is generally unlikely that a pharmaceutical company would normally submit a disinvestment request to CONITEC for a medicine within a treatment group. This would generally only be possible with a 'one in, one out' policy, in which only full withdrawal and substitutions were possible. This typically only takes place within countries once generics become available in a class, or related class, to stop the prescribing of a more expensive patented product, without compromising care [5, 53-56]. This could also represent a change in the 'add-on' (with escalating prices) paradigm of new more effective patented technologies in a class, which can be a concern to health authorities, as seen for instance with new cancer medicines [57-60].

\section{Conclusions}

This was the first case of a disinvestment decision in Brazil based on effectiveness using different approaches, including real-world data, following the adoption of the national guideline for technology performance assessment in Brazil [7, 61]. The decision will be fully implemented after the update of the clinical guideline for MS. Until this occurs, the disinvestment decision based on the various studies conducted, including meta-analyses and real-world studies, remains at the mercy of revocation requests.

We hope this process in Brazil will be of interest to other countries, especially those providing universal healthcare, as they seek to better manage both investment and disinvestment decisions with finite resources $[5,60,62]$. Future research will concentrate on evaluating the challenges of this disinvestment process, including the possible rise in judicial requests in Brazil and their costs, building on previous cases [37].

Author contributions LLPdeL, AAG Jnr, MS, CM, ID, KS, RGP, JA, BG, MB, IRZ, VCCdS, CAP and FdeAA helped design the various studies. $\mathrm{MS}$ and $\mathrm{CM}$ conducted the initial meta-analysis. LLPdeL, AAG Jnr, ID, KS, RGP, JA and FdeAA undertook the realworld studies. All authors contributed to the analysis. LLPdeL, AAG Jnr, JA, BG and FdeAA produced the initial draft, with all authors contributing to successive editions before submission. All authors contributed to the revised paper following reviewer comments.

\section{Compliance with Ethical Standards}

Funding CCATES-UFMG received support from the Ministry of Health of Brazil through resource transfer from the National Health Fund (TED 78/2015). NATS-INC received support from the Ministry of Health of Brazil (BR/LOA 1500033.001).

Conflict of interest KS, IRZ, VCCdS and CAP work directly for the Ministry of Health in Brazil. However, all authors (LLPdeL, AAG Jnr, MS, CM, ID, KS, RGP, JA, BG, MB, IRZ, VCCdS, CAP and FdeAA) declare they have no other relevant conflicts of interest.

Data availability The references used in the Cochrane review as well as our own analysis are provided in this paper for researchers to access. Unfortunately, the SUS database is owned by the Brazilian 
Government, with very tight controls of access. No data can be analysed apart from by approved research institutions in Brazil, with strict access criteria and controls. This is similar to accessing patientlevel data in other countries, such as Scotland and Sweden.

Open Access This article is distributed under the terms of the Creative Commons Attribution-NonCommercial 4.0 International License (http://creativecommons.org/licenses/by-nc/4.0/), which permits any noncommercial use, distribution, and reproduction in any medium, provided you give appropriate credit to the original author(s) and the source, provide a link to the Creative Commons license, and indicate if changes were made.

\section{References}

1. Atos do Poder Legislativo, República Federativa do Brasil. Lei No 12.401, de 28 de abril de 2011. Diário Oficial da União. Brasília, DF: Imprensa Nacional; 2011. p. 1-2.

2. Maloney MA, Schwartz L, O'Reilly D, Levine M. Drug disinvestment frameworks: components, challenges, and solutions. Int J Technol Assess Health Care. 2017;33(2):261-9.

3. Orso M, de Waure C, Abraha I, Nicastro C, Cozzolino F, Eusebi $P$, et al. Health technology disinvestment worldwide: overview of programs and possible determinants. Int J Technol Assess Health Care. 2017;33(2):239-50.

4. Brett J, Elshaug AG, Bhatia RS, Chalmers K, Badgery-Parker T, Pearson S-A. A methodological protocol for selecting and quantifying low-value prescribing practices in routinely collected data: an Australian case study. Implement Sci. 2017;12(1):58.

5. Parkinson B, Sermet C, Clement F, Crausaz S, Godman B, Garner S, et al. Disinvestment and value-based purchasing strategies for pharmaceuticals: an international review. Pharmacoeconomics. 2015;33:905-24.

6. Casa Civil da República Federativa do Brasil. Decreto n ${ }^{\circ}$ 7.646, de 21 de dezembro de 2011. Diário Oficial da União. Brasília, DF: Imprensa Nacional; 2011. p. 3-5.

7. Guerra-Júnior AA, Lemos L, Godman B, Bennie M, Osorio de Castro C, Alvares $\mathrm{J}$, et al. Health technology performance assessment: real-world evidence for public healthcare sustainability. Int J Technol Assess Health Care. 2017;33(2):279-28.

8. da Gama Pereira ABCN, Lacativa MCS, da Costa Pereira FFC, Alvarenga RMP. Prevalence of multiple sclerosis in Brazil: a systematic review. Mult Scler Relat Disord. 2015;4:572-9.

9. Compston A, Coles A. Multiple sclerosis. Lancet. 2008;372:1502-17.

10. Hauser SL, Goodwin DS. Multiple sclerosis and other demyelinating diseases. In: Fauci AS, Braunwald E, Kasper DL, Hauser SL, editors. Harrison's principles of internal medicine. 17th ed. New York: McGraw-Hill Medical; 2008. p. 2611-21.

11. Ransohoff RM, Hafler DA, Lucchinetti CF. Multiple sclerosis-a quiet revolution. Nat Rev Neurol. 2015;11:246-246.

12. Runmarker B, Andersen O. Prognostic factors in a multiple sclerosis incidence cohort with twenty-five years of follow-up. Brain. 1993;116:117-34.

13. Confavreux C, Vukusic S, Moreau T, Adeleine P. Relapses and progression of disability in multiple sclerosis. N Engl J Med. 2000;343:1430-8.

14. Weinshenker BG, Bass B, Rice GP, Noseworthy J, Carriere W, Baskerville $\mathrm{J}$, et al. The natural history of multiple sclerosis: a geographically based study. I. Clinical course and disability. Brain. 1989;112(Pt 1):133-46.
15. Lublin FD, Reingold SC, Cohen JA, Cutter GR, Sørensen PS, Thompson AJ, et al. Defining the clinical course of multiple sclerosis: the 2013 revisions. Neurology. 2014;83:278-86.

16. Goldenberg MM. Multiple sclerosis review. $\mathrm{P} T$. 2012;37:175-84.

17. Havrdova E, Galetta S, Hutchinson M, Stefoski D, Bates D, Polman $\mathrm{CH}$, et al. Effect of natalizumab on clinical and radiological disease activity in multiple sclerosis: a retrospective analysis of the Natalizumab Safety and Efficacy in RelapsingRemitting Multiple Sclerosis (AFFIRM) study. Lancet Neurol. 2009;8:254-60.

18. Ingwersen J, Aktas O, Hartung H-P. Advances in and algorithms for the treatment of relapsing-remitting multiple sclerosis. Neurotherapeutics. 2016;13:47-57.

19. Radick L, Mehr SR. The latest innovations in the drug pipeline for multiple sclerosis. Am Health Drug Benefits. 2015;8:448-53.

20. Secretaria de Atenção à Saúde, Ministério da Saúde, República Federativa do Brasil. Portaria ${ }^{\circ}$ 97, de 22 de março de 2001. Diário Oficial da União. Brasília, DF: Imprensa Nacional; 2001. p. 114.

21. Secretaria de Atenção à Saúde, Ministério da Saúde, República Federativa do Brasil. Portaria ${ }^{\circ}$ 391, de 5 de maio de 2015. Diário Oficial da União. Brasília, DF: Imprensa Nacional; 2015. p. 40.

22. Filippini G, Munari L, Incorvaia B, Ebers GC, Polman C, D'Amico $\mathrm{R}$, et al. Interferons in relapsing remitting multiple sclerosis: a systematic review. Lancet. 2003;361(9357):545-52.

23. Mikol DD, Barkhof F, Chang P, Coyle PK, Jeffery DR, Schwid $\mathrm{SR}$, et al. Comparison of subcutaneous interferon beta-1a with glatiramer acetate in patients with relapsing multiple sclerosis (the REbif vs Glatiramer Acetate in Relapsing MS Disease [REGARD] study): a multicentre, randomised, parallel, open-label trial. Lancet Neurol. 2008;7:903-14.

24. O'Connor P, Filippi M, Arnason B, Comi G, Cook S, Goodin D, et al. 250 microg or 500 microg interferon beta- $1 \mathrm{~b}$ versus $20 \mathrm{mg}$ glatiramer acetate in relapsing-remitting multiple sclerosis: a prospective, randomised, multicentre study. Lancet Neurol. 2009;8:889-97.

25. Tramacere I, Del Giovane C, Salanti G, D’Amico R, Filippini G. Immunomodulators and immunosuppressants for relapsingremitting multiple sclerosis: a network meta-analysis. Cochrane Database Syst Rev. 2015;9:CD011381. https://doi.org/10.1002/ 14651858.CD011381.pub2.

26. Higgins JPT, Altman DG, Gøtzsche PC, Jüni P, Moher D, Oxman $\mathrm{AD}$, et al. The Cochrane Collaboration's tool for assessing risk of bias in randomised trials. BMJ $\mathrm{Br}$ Med $\mathrm{J}$ Publ Group. 2011;343:d5928.

27. Hoaglin DC, Hawkins N, Jansen JP, Scott DA, Itzler R, Cappelleri JC, et al. Conducting indirect-treatment-comparison and network-meta-analysis studies: report of the ISPOR Task Force on Indirect Treatment Comparisons Good Research Practices: part 2. Value Health. 2011;14:429-37.

28. The IFNB Multiple Sclerosis Study Group. Interferon beta-1b is effective in relapsing-remitting multiple sclerosis: I. Clinical results of a multicenter, randomized, double-blind, placebo-controlled trial. Neurology. 1993;43:655-655.

29. Jacobs LD, Cookfair DL, Rudick RA, Herndon RM, Richert JR, Salazar AM, et al. Intramuscular interferon beta-1a for disease progression in relapsing multiple sclerosis. The Multiple Sclerosis Collaborative Research Group (MSCRG). Ann Neurol. 1996;39:285-94.

30. Randomised double-blind placebo-controlled study of interferon beta-1a in relapsing/remitting multiple sclerosis. PRISMS (Prevention of Relapses and Disability by Interferon beta-1a Subcutaneously in Multiple Sclerosis) Study Group. Lancet. 1998;352(9139):1498-504. 
31. Khan OA, Tselis AC, Kamholz JA, Garbern JY, Lewis RA, Lisak RP. A prospective, open-label treatment trial to compare the effect of IFNbeta-1a (Avonex), IFNbeta-1b (Betaseron), and glatiramer acetate (Copaxone) on the relapse rate in relapsingremitting multiple sclerosis: results after 18 months of therapy. Mult Scler. 2001;7:349-53.

32. Durelli L, Verdun E, Barbero P, Bergui M, Versino E, Ghezzi A, et al. Every-other-day interferon beta-1b versus once-weekly interferon beta-1a for multiple sclerosis: results of a 2-year prospective randomised multicentre study (INCOMIN). Lancet. 2002;359:1453-60.

33. Koch-Henriksen N, Sørensen PS, Christensen T, Frederiksen J, Ravnborg M, Jensen K, et al. A randomized study of two interferon-beta treatments in relapsing-remitting multiple sclerosis. Neurology. 2006;66:1056-60.

34. Etemadifar M, Janghorbani M, Shaygannejad V. Comparison of Betaferon, Avonex, and Rebif in treatment of relapsing-remitting multiple sclerosis. Acta Neurol Scand. 2006;113:283-7.

35. Schwid SR, Panitch HS. Full results of the Evidence of Interferon Dose-Response-European North American Comparative Efficacy (EVIDENCE) study: a multicenter, randomized, assessor-blinded comparison of low-dose weekly versus high-dose, high-frequency interferon beta-1a for relapsing multiple sclerosis. Clin Ther. 2007;29:2031-48.

36. Lublin FD, Cofield SS, Cutter GR, Conwit R, Narayana PA, Nelson F, et al. Randomized study combining interferon and glatiramer acetate in multiple sclerosis. Ann Neurol. 2013;73:327-40.

37. de Caires Souza AL, de Souza ALC, de Assis Acurcio F, Júnior AAG, do Nascimento RCRM, Godman B, et al. Insulin glargine in a Brazilian state: should the government disinvest? An assessment based on a systematic review. Appl Health Econ Health Policy. 2014;12:19-32.

38. Secretaria de Ciência, Tecnologia e Insumos Estratégicos, Ministério da Saúde, República Federativa do Brasil. Portaria n ${ }^{\circ} 27$, de 6 de julho de 2016. Diário Oficial da União. Brasília, DF: Imprensa Nacional; 2016. p. 35.

39. Drugs@FDA: FDA approved drug products. http://www.fda.gov/ drugsatfda. Accessed 16 May 2017.

40. Consulta a produtos registrados - Anvisa [Internet]. http://portal. anvisa.gov.br/consulta-produtos-registrados. Accessed 16 May 2017.

41. Henshall C, Schuller T, Mardhani-Bayne L. Using health technology assessment to support optimal use of technologies in current practice: the challenge of "disinvestment". Int J Technol Assess Health Care. 2012;28:203-10.

42. CADTH. Canadian Agency for Drugs and Technologies in Health. Comparative clinical and cost-effectiveness of drug therapies for relapsing-remitting multiple sclerosis. https://www. cadth.ca/sites/default/files/pdf/TR0004_RRMS_ScienceReport_e. pdf. Accessed 23 May 2017.

43. NICE. Technology appraisal guidance 32. Beta interferon and glatiramer acetate for the treatment of multiple sclerosis. 2002. https://www.nice.org.uk/Guidance/TA32. Accessed 24 May 2017.

44. Boggild M, Palace J, Barton P, Ben-Shlomo Y, Bregenzer T, Dobson C, et al. Multiple sclerosis risk sharing scheme: two year results of clinical cohort study with historical comparator. BMJ. 2009;339:b4677.

45. Raftery J. Multiple sclerosis risk sharing scheme: a costly failure. BMJ. 2010;340:c1672.

46. Palace J, Duddy M, Bregenzer T, Lawton M, Zhu F, Boggild M, et al. Effectiveness and cost-effectiveness of interferon beta and glatiramer acetate in the UK Multiple Sclerosis Risk Sharing Scheme at 6 years: a clinical cohort study with natural history comparator. Lancet Neurol. 2015;14(5):497-505.
47. Calabresi PA, Kieseier BC, Arnold DL, Balcer LJ, Boyko A, Pelletier $\mathrm{J}$, et al. Pegylated interferon beta-1a for relapsingremitting multiple sclerosis (ADVANCE): a randomised, phase 3, double-blind study. Lancet Neurol. 2014;13:657-65.

48. Top multiple sclerosis drugs worldwide by revenue 2013 । Statistic [Internet]. Statista. [cited 2017 May 5]. https://www. statista.com/statistics/372273/leading-ten-ms-medications-byrevenue/. Accessed 31 May 2017.

49. Aitken M, Kleinrock M, Pennente K, Lyle J, Nass D, Caskey L. Medicines use and spending in the U.S. A review of 2015 and outlook to 2020 [Internet]. IMS Institute for Healthcare Informatics; 2016. http://www.imshealth.com/en/thought-leadership/ quintilesims-institute/reports/medicines-use-and-spending-in-theus-a-review-of-2015-and-outlook-to-2020. Accessed 31 May 2017.

50. Secretaria de Ciência, Tecnologia e Insumos Estratégicos, Ministério da Saúde, República Federativa do Brasil. Portaria $n^{\circ} 19$, de 19 de abril de 2017. Diário Oficial da União. Brasília, DF: Imprensa Nacional; 2017. p. 58.

51. Secretaria de Ciência, Tecnologia e Insumos Estratégicos, Ministério da Saúde, República Federativa do Brasil. Portaria no ${ }^{\circ}$ 14, de 13 de março de 2017. Diário Oficial da União. Brasília, DF: Imprensa Nacional; 2017. p. 53.

52. FIOCRUZ. Technology transfer beta interferons. https://agencia. fiocruz.br/assinado-acordo-para-transfer\%C3\%AAncia-de-tecnolo gia-do-betainterferona-1a. Accessed 5 Apr 2017.

53. Godman B, Schwabe U, Selke G, Wettermark B. Update of recent reforms in Germany to enhance the quality and efficiency of prescribing of proton pump inhibitors and lipid-lowering drugs. Pharmacoeconomics. 2009;27(5):435-8.

54. Hesse U, Godman B, Petzold M, Martin A, Malmstrom RE. Impact of delisting ARBs, apart from losartan, on ARB utilisation patterns in Denmark: implications for other countries. Appl Health Econ Health Policy. 2013;11(6):677-85.

55. Martin A, Godman B, Miranda J, Tilstone J, Saleem N, Olsson E, et al. Measures to improve angiotensin receptor blocker prescribing efficiency in the UK: findings and implications. J Comp Effect Res. 2014;3(1):41-51.

56. Sakshaug S, Furu K, Karlstad O, Ronning M, Skurtveit S. Switching statins in Norway after new reimbursement policy: a nationwide prescription study. $\mathrm{Br} \mathrm{J}$ Clin Pharmacol. 2007;64(4):476-81.

57. Howard DH, Bach PB, Berndt ER, Conti RM. Pricing in the market for anticancer drugs. J Econ Perspect. 2015;29:139-62.

58. Tefferi A, Kantarjian H, Rajkumar SV, Baker LH, Abkowitz JL, Adamson JW, et al. In support of a patient-driven initiative and petition to lower the high price of cancer drugs. Mayo Clin Proc. 2015;90:996-1000.

59. Ghinea N, Kerridge I, Lipworth W. If we don't talk about value, cancer drugs will become terminal for health systems [Internet]. The Conversation. 2015. http://theconversation.com/if-we-donttalk-about-value-cancer-drugs-will-become-terminal-for-healthsystems-44072. Accessed 15 May 2017.

60. Godman B, Malmström RE, Diogene E, Gray A, Jayathissa S, Timoney A, et al. Are new models needed to optimize the utilization of new medicines to sustain healthcare systems? Expert Rev Clin Pharmacol. 2015;8:77-94.

61. Brasil. Ministério da Saúde. Secretaria de Ciência, Tecnologia e Insumos Estratégicos. Departamento de Gestão e Incorporação de Tecnologias em Saúde. Methodological Guidelines: Health Technology Performance Assessment. Brasília, DF: Ministério da Saúde do Brasil

62. Malmström RE, Godman BB, Diogene E, Baumgärtel C, Bennie M, Bishop I, et al. Dabigatran - a case history demonstrating the need for comprehensive approaches to optimize the use of new drugs. Front Pharmacol. 2013;4:1-31. 